\begin{tabular}{cc|c}
\hline Tar. Bil.Der. & $\begin{array}{c}\text { Tarım Bilimleri Dergisi } \\
\text { Dergi web sayfası: }\end{array}$ & Journal of Agricultural Sciences \\
& www.agri.ankara.edu.tr/dergi & Journal homepage: \\
& www.agri.ankara.edu.tr/journal
\end{tabular}

\title{
Asma Yapră̆ının (Vitis vinifera L.) Mikrodalga Enerjisiyle Kurutulması ve Bazı Kalite Parametrelerinin Belirlenmesi
}

\author{
İlknur ALIBBAŞ ${ }^{\mathbf{a}}$ \\ ${ }^{a}$ Uludağ Üniversitesi, Ziraat Fakültesi, Biyosistem Mühendisliği Bölümü, 16059, Bursa, TÜRKİYE
}

\section{ESER BİLGİSI}

Araştırma Makalesi — Tarım TeknolojileriＤOI: 10.1501/Tarimbil_0000001191

Sorumlu Yazar: İlknur ALİBAŞ, e-posta: ialibas@uludag.edu.tr, Tel:- +90(224) 2941608

Geliş tarihi: 11 Ağustos 2011, Düzeltmelerin gelişi: 26 Mart 2012, Kabul: 24 Nisan 2012

\begin{abstract}
ÖZET
İlk nem seviyesi yaş baza göre \% $75.35( \pm 0.02)$ olan $50( \pm 0.05)$ g ağırlı̆̆ındaki asma (Vitis vinifera L.) yaprakları yaş baza göre nem seviyesi \% $9.13( \pm 0.12)$ oluncaya dek 17,15 ve $13 \mathrm{~W} \mathrm{~g}^{-1}$ mikrodalga güç yoğunluk seviyelerinde kurutulmuşlardır. Kurutma işlemleri 3 farklı güç yoğunluğunda gerçekleştirilmiş ve kurutma süresi güç yoğunluğuna bağlı olarak 210 - $270 \mathrm{~s}$ sürmüştür. Bu çalışmada, 7 farklı ince tabaka kurutma modelinin yanı sıra Midilli et al eşitliğinden türetilmiş olan ve Alibas yaklaşımı olarak adlandırılmış yeni bir kurutma yaklaşımı ile deneysel olarak elde edilen veriler modellenmiştir. Regresyon katsayısının $\left(R^{2}\right)$ en büyük olduğu, standart hata $(S H)$, ki kare $\left(\chi^{2}\right)$ ve ortalama karesel hata $(O K H)$ değerlerinin ise en küçük olduğu model en iyi model olarak seçilmiştir. Buna göre çalışmada kullanılan üç farklı mikrodalga güç yoğunluğunda da elde edilen deneysel verilere en yakın sonuçları veren model Alibas modeli olarak belirlenmiştir. Çalışmada ayrıca mikrodalga ışınlarla kurutulan asma yapraklarının renk ve askorbik asit değerleri taze asma yapraklarının renk ve askorbik asit değerleri ile karşılaştırılmıştır. Buna göre taze ürüne en yakın renk ve askorbik asit değerinin $15 \mathrm{~W} \mathrm{~g}^{-1}$ güç yoğunluğundaki mikrodalga kurutma sırasında elde edildiği anlaşılmıştır.
\end{abstract}

Anahtar sözcükler: Askorbik asit; Asma yaprağı; Mikrodalga kurutma; İnce tabaka kurutma modelleri; Renk

\section{Microwave Drying of Grapevine (Vitis vinifera L.) Leaves and Determination of Some Quality Parameters}

\section{ARTICLE INFO}

Research Article - Agricultural Technologies

Corresponding author: İlknur ALİBAŞ, e-mail: ialibas@uludag.edu.tr, Tel: +90(224) 2941608

Received: 11 August 2011, Received in revised form: 26 March 2012, Accepted: 24 April 2012

\begin{abstract}
Grapevine (Vitis vinifera L.) leaves with $50( \pm 0.05) \mathrm{g}$ weight and $75.35 \%( \pm 0.02)$ humidity on wet basis were dried in microwave oven at 17,15 ve $13 \mathrm{~W} \mathrm{~g}^{-1}$ microwave power densities, until the humidity fell down to $9.13 \%( \pm 0.12)$ on wet basis. Drying processes were completed between 210 and $270 \mathrm{~s}$ depending on microwave power density levels. In this study, measured values were compared with predicted values obtained from 7 thin layer drying
\end{abstract}


equations with a new thin layer drying equation and a new model is called Alibas (equation is derived from Midilli et al). In this study, within applied microwave power densities; models whose coefficient of regression $\left(R^{2}\right)$ are highest and standard error of estimated $(S E E)$, root mean square error $(O K H)$ and chi-square $\left(\chi^{2}\right)$ are lowest were chosen to be the best models. According to this, the best model at the all temperature levels was found to be Alibas model. The best quality in terms of colour and ascorbic acid values were obtained in the drying period with $15 \mathrm{~W}$ $\mathrm{g}^{-1}$ microwave power density.

Keywords: Ascorbic acid; Grapevine leaves; Microwave drying; Thin layer drying models; Colour

(C) Ankara Üniversitesi Ziraat Fakültesi

\section{Giriş}

Asma yaprağı, Türk yemek kültüründe önemli bir yere sahip olan besleyici bir tarımsal üründür. İçeriğinde bol miktarda askorbik asit (C vitamini), A vitamini, D vitamini, B1 ve B2 vitamini, kalsiyum ve demir bulundurmaktadır (Eriş \& Şeniz 1997). Ayrıca bol lif içermesi bakımından diyet ürünü olarak da kullanılabilmektedir. Besin içeriğinin oldukça fazla olmasından dolayı (Eriş \& Şeniz 1997) asma yaprağı kurutularak baharat haline getirilebilir. Böylece besin içeriği bakımından asma yaprağından maksimum oranda fayda sağlanabilir.

Tarımsal ürünler hasat edildikten sonra da solunum faaliyetlerine davam ettikleri için hızlı bir şekilde bozulmaya başlarlar. Ürünlerin hasat işleminden sonra kullanım sürelerinin artırılması için pek çok yöntem bulunmaktadır. $\mathrm{Bu}$ yöntemlerden biri de kurutma yöntemidir. Kurutma üründeki nemin hızlı bir şekilde üründen uzaklaştırılması olarak tanımlanmaktadır. (Alibas 2006; Ertekin \& Yaldız 2004). Tarımsal ürünlerin kurutulması için pek çok kurutma yöntemi bulunmaktadır. Kurutulan materyalin toz, böcek ve mikroorganizmalara maruz kalması gibi pek çok dezavantajı barındıran güneşte kurutma yöntemi dünyada ve ülkemizde yaygın olarak kullanılan geleneksel bir kurutma yöntemidir (Toğrul 2006). Sicak havayla kurutma yöntemi ise materyalin besin içeriğinde kayıplara neden olması, enerji tüketiminin fazla ve kurutma zamanının uzun olması gibi dezavantajlara sahiptir (Alibas Ozkan et al 2007). Bu nedenle son yıllarda hızlı kurutma sağlaması, enerji tüketiminin az olması ve besin içeriğinin korunması gibi önemli sebeplerden dolayı mikrodalga işınlarla kurutma yöntemi yaygın olarak kullanılan bir yöntem haline gelmiştir (Maskan 2001; Torringa et al 2001; Soysal 2004; Alibas 2006).

Mikrodalga kurutma yöntemi ile 1sirgan (Alibas 2007; Alibas 2010), pazı yaprakları (Alibas 2006), maydanoz (Soysal 2004; Soysal et al 2006), ispanak (Alibas Ozkan et al 2006), nane (Özbek \& Dadali 2007), yeşil çay (Kadlec et al 2001), kereviz yaprağı (Demirhan \& Ozbek 2011), semizotu (Demirhan \& Ozbek 2010a), fesleğen (Demirhan \& Ozbek 2010b, 2010c) gibi pek çok yeşil yapraklı tarımsal ürün kurutulmuştur.

İnce tabaka kurutma işlemlerinde kurutulacak örnekler kurutma alanına tek tabaka olacak şekilde yerleştirilir. İnce tabaka kurutma kuramını tanımlayan pek çok deneysel, yarı deneysel ve teorik model bulunmaktadır (Ozdemir \& Devres 1999; Midilli \& Kucuk 2003). İnce tabaka kurutma sürecinin matematiksel olarak modellenmesi kurutma sistemlerinin performansının artırılması açısından son derece önemlidir (Cihan et al 2007).

$\mathrm{Bu}$ çalışmanın amacı; i) asma yapraklarının ince tabaka kurutma kinetiğinin belirlenmesi, ii) deneysel olarak elde edilen kurutma verilerinin, literatürde daha önce tanımlanmıș olan 7 farklı ince tabaka kurutma modeline göre ve Midilli et al (2002) modelinden türetilmiş olan Alibas modeline göre tahmin edilen verilerle karşılaştırılması, iii) deneysel verilere en yakın sonuçları veren en iyi matematiksel modelin seçilmesi, iv) kurutulan örneklerin renk ve askorbik asit içeriğinin taze ürünlerle karşılaştırılması ve kalite parametreleri açısından en uygun mikrodalga kurutma seviyesinin tespit edilmesidir. 


\section{Materyal ve Yöntem}

\subsection{Materyal}

Kurutulmak üzere hasat edilen asma (Vitis vinifera L.) yaprakları Manisa'nın Sarı̈öl İlçesindeki bir asma bahçesinden hasarsız olanları seçilerek hasat edilmiştir. Asma yaprakları kurutma işlemlerinden önce nem kaybetmemesi için rslak yastıklarla çevrelenerek $4 \pm 0.5^{\circ} \mathrm{C}$ sıcaklığında bekletilmiştir (Alibas 2006). Sıcaklığı $105^{\circ} \mathrm{C}$ olan kurutma firınında 24 saat süreyle bekletilen asma yapraklarının ilk ve son nem oranları, kurutma fırını öncesi ve sonrası ağırlık ölçümlerinden yola çıkılarak belirlenmiştir.

\subsection{Kurutma ekipmanlarl ve kurutma yöntemi}

Kurutma denemeleri teknik özellikleri $230 \mathrm{~V}$, $50 \mathrm{~Hz}$ ve $2900 \mathrm{~W}$ olan programlanabilir bir fırında (Arcelik MD 592, Türkiye) yapılmıştır. Kurutma firınının alanı $327 \times 370 \times 207 \mathrm{~mm}$ boyutlarındadır ve kurutma alanının tabanının ortasında çapı $280 \mathrm{~mm}$ olan cam bir kurutma tablası bulunmaktadır. Kurutma tablası $360^{\circ}$ dönmekte ve her 5 dakikada bir ya da kapak her açılıp kapatıldığında dönüş yönünü değiştirmektedir. Kurutma zamanı fırının üzerindeki dijital bir saat aracılığıyla ölçülmektedir. Fırın, 1000, 850, 750, 650, 500, 350,160 ve $90 \mathrm{~W}$ olan 8 farklı mikrodalga güç seviyesinde çalışabilmektedir. Fırın programlanabilme özelliğine sahip olan dijital mikrodalga firının kontrol panosunda dijital bir zaman göstergesi bulunmaktadır.

Kurutma denemeleri, yapraklı ürünlerin kurutulmasında yaygın olarak kullanılan ve besin içeriğinin en besin içeriğinin iyi korunduğu güç yoğunlukları olarak daha önce literatürde tanımlanmış olan 850,750 ve $650 \mathrm{~W}$ mikrodalga güç seviyelerinde gerçekleştirilmiştir (Soysal 2004; Alibas 2007; Alibas Ozkan 2007; Alibas 2010). Kurutulan örnekler ağırlıkları $50( \pm 0.06) \mathrm{g}$ olacak şekilde tartılmıştır. Mikrodalga güç yoğunluğu değeri ise, kurutma işleminin gerçekleştirildiği mikrodalga gücünün örnek ağırlığına bölünmesiyle bulunmaktadır. Kurutulan asma yaprakları sağlıklı ve zarar görmemiş kısımlardan özenle seçilmiştir. Denemeler üç tekrarlı olarak yapılmıştır. Mikrodalga kurutma kinetiğinin belirlenmesi açısından her 30 saniyede bir firın açılarak örneklerden $0.01 \mathrm{~g}$ hassasiyete sahip dijital bir tartım aleti (Alsep EX 2000A, Almanya) yardımıyla ağırlık ölçümü alınmıştır. Tüm ağırlık ölçüm işlemleri kurutma rejiminin bozulmaması açısından 10 saniye içinde tamamlanmıştır (Alibas 2010).

Ağırlık ölçümlerinden yola çıkılarak çeşitli hesaplamalar yapılmıştır. Kuru baza göre ilk nem içeriği aşağıdaki eşitlik kullanılarak hesaplanmıştır:

$M_{0}=\frac{\left(W_{o}-W_{k}\right)}{W_{k}}$

Burada; $M_{0}$, materyalin ilk nem içeriği [( $\left.\mathrm{kg} \mathrm{su}\right)$ (kg kuru madde $\left.\left.{ }^{-1}\right)\right] ; W_{0}$, örneklerin ilk andaki ağırlığ $(\mathrm{kg})$ ve $W_{\mathrm{k}}$, örneklerin toplam kuru ağırlığıdır (kg). Ayrılabilir nem oranı (MR) aşağıdaki eşitlik kullanılarak hesaplanmıştır (Yağcioğlu 1999):

$M R=\frac{M-M_{e}}{M_{o}-M_{e}}$

Burada; $M$, herhangi bir andaki nem içeriği $[(\mathrm{kg}$ su) (kg kuru madde $\left.{ }^{-1}\right)$ ] ve $M_{\mathrm{e}}$, denge nem içeriği [(kg su) (kg kuru madde $\left.\left.{ }^{-1}\right)\right] . M_{\mathrm{e}}$, değeri mikrodalga kurutma işlemleri için yokumsanmıştır (Maskan 2000; Soysal 2004). Çalışmada ayrılabilir nem oranı değeri sadeleştirilerek $M R=M / M_{0}$ olarak kullanılmıştır. Kuruma hızı (DR), aşağıdaki eşitlik kullanılarak hesaplanmaktadır:

$D R=\frac{M_{t+d t}-M_{t}}{d_{t}}$

Burada; $M_{\mathrm{t}}, t$ anındaki ve $M_{t+\mathrm{d} t}, t+\mathrm{d} t$ aralığındaki nem içeriği [( kg su) (kg kuru madde $\left.\left.{ }^{-1}\right)\right]$ olup $D R$ ise kuruma hizidir [( $\mathrm{kg} \mathrm{su})$ (kg kuru madde $)^{-1}$ ] (Karaaslan \& Tunçer 2008, Doymaz et al 2006).

\subsection{Askorbik asit ve renk ölçüm yöntemleri}

Asma yapraklarının askorbik asit içeriği, $520 \mathrm{~nm}$ çözünürlük değerinde sahip Shimadzu UV-120-01 spektrofotometresiyle okunmuştur. Örnekler okuma işlemlerinden önce \%4'lük oksalik asit çözeltisine batırılmışlardır. 
Renk okumaları, yaprakların her iki yanından da ölçüm alınarak gerçekleştirilmiştir. Ortalamayı temsil eden 10 adet yapraktan alınan ölçümlerin ortalamaları ile renk kriterleri belirlenmiştir. Renge ilişkin $L$ (parlaklık), $a$ (yeşillik), $b$ (sarılık) değerlerinin ölçülmesinde Minolta CR 400 renk ölçüm cihazı kullanılmıştır. $\mathrm{Bu}$ değerlerden yararlanılarak diğer renk kriterleri olan rengin kroması (C) ve renk açısı $(\alpha)$ ise aşağıdaki eşitlikler kullanılarak hesaplama yöntemi ile bulunmuştur (Alibas 2006):

$$
\begin{aligned}
& C=\sqrt{a^{2}+b^{2}} \\
& \alpha=\tan ^{-1}(b / a)
\end{aligned}
$$

\subsection{Veri analizi}

Calıșma, 3 tekerrürlü olarak kurulmuștur. Elde edilen verilerin ortalamaları ve diğer istatistik hesaplamaları SPSS 17.0 istatistik programıla yapılmıştır.

Literatürde daha önce tanımlanmış olan 8 farklı deneysel, yarı deneysel ve teorik ince tabaka kurutma modelinin yanı sira Midilli et al yaklaşımından türetilmiş olan Alibas modeline ait eşitlikler Çizelge 1'de verilmiştir. Doğrusal olmayan regresyon analizleri, Çizelge 1'deki eşitlikler kullanılarak SPSS 17.0 istatistik programı kullanılarak gerçekleştirilmiştir. Çizelge 1 'de tanımlanan eşitliklere ait kurutma sabit ve katsayıları $\left(k, a, a_{0}, b, c, g\right.$, ve $\left.n\right)$ doğrusal olmayan regresyon analizleri ile hesaplanmıştır.

Kurutma sabit ve katsayılarının varyasyonlarının $\quad(y)$ oluşturulması için mikrodalga güç yoğunluğunu içeren 5 farklı eşitlik tanımlanmıştır (Guarte 1996; Ertekin \& Yaldız 2004). Bu eşitlikler, lineer tip $(Y=a+b X)$, logaritmik tip $(Y=a+b \ln (X))$, güç tipi $\left(Y=a X^{b}\right)$, exponental tip $(Y=a \exp (b X))$ ve arrhenius tip $(Y=a \exp (b / X)) \quad$ şekilde tanımlanmıştır. $\quad \mathrm{Bu}$ çalışmada regresyon katsayısının en yüksek olduğu model, optimum model olarak tanımlanmış ve optimum model eşitliği mikrodalga güç yoğunluk değerlerini içeren formulasyonlar oluşturulması amaciyla Arrhenius tip matematiksel eşitlikle, SPSS 17.0 istatistik programı kullanılarak sabit ve katsayılarına $\left(k_{1}, k_{2}\right.$, $a_{1}, a_{2}, b_{1}, b_{2}, g_{1}, g_{2}, n_{1}$ ve $\left.n_{2}\right)$ ayrılmıştır.

\subsection{Matematiksel hesaplamalar}

Regresyon katsayısı $\left(R^{2}\right)$ asma yapraklarının sicak havayla kurutulmasinda en uygun matematiksel modelin seçiminde başlica kriter olmuştur. Tahminin standart hatası $(\mathrm{SH})$ kurutma işlemleri boyunca tüm ölçüm aralıklarında ölçülen ve tahmin edilen veriler arasındaki farkı vermektedir ve ideal değeri " 0 " olmalıdır. Tahminin standart hatası aşağıdaki eşitlik kullanılarak hesaplanmaktadır:

$S H=\sqrt{\frac{\sum_{i=1}^{N}\left(M_{R_{\text {exp }, i}}-M_{R_{p r e, i}}\right)^{2}}{N-n_{i}}}$

Burada; $n_{\mathrm{i}}$ sabit ve katsayıların sayısıdır.

Modelin kısa vadeli performansını belirlemede kullanılan ortalama karesel hata $(O K H)$ ve aşağıdaki eşitlik kullanılarak hesaplanmıştır:

$O K H=\sqrt{\frac{\sum_{i=1}^{N}\left(M_{R_{p r e, i}}-M_{R_{\exp , i}}\right)^{2}}{N}}$

$\mathrm{Ki}$ kare $\left(\chi^{2}\right)$ is deneysel ve tahmin verileri ortalamalarının karesidir ve modelin etkinliği için bu değerin mümkün olduğunca küçük olması gerekmektedir. Ki kare değeri aşağıdaki eşitlik kullanılarak hesaplanmıştır:

$\chi^{2}=\frac{\sum_{i=1}^{N}\left(M_{R_{\mathrm{exp}, i}}-M_{R_{\text {pre }, i}}\right)^{2}}{N-n_{i}}$

\section{Bulgular ve Tartışma}

\subsection{Kurutma ĕgrileri ve matematiksel modelleme}

Asma yapraklarının kurutulmasındaki nem-zaman diyagramı Şekil 1'de verilmiştir. İlk nem seviyesi kuru baza göre 4.08 (\% $75.35 \mathrm{yb}$ ) ve ilk ağırlıkları $50( \pm 0.06)$ g olan asma yaprakları nem seviyesi kuru baza göre $0.144( \pm 0.005)$, yaş baza göre ise $\% 9.13( \pm 0.12)$ oluncaya dek 17,15 ve $13 \mathrm{~W} \mathrm{~g}^{-1}$ mikrodalga güç yoğunluk seviyelerinde kurutulmuştur. Kurutma işlemleri $17 \mathrm{~W} \mathrm{~g}^{-1}$ mikrodalga güç yoğunluğunda 210 saniye, 15 $\mathrm{W} \mathrm{g}^{-1}$ mikrodalga güç yoğunluğunda 240 saniye ve $13 \mathrm{~W} \mathrm{~g} \mathrm{~g}^{-1}$ mikrodalga güç yoğunluğunda ise 270 saniye sürmüştür. Mikrodalga enerjisinin 
Çizelge 1-İnce tabaka kurutma tahminler için kullanılan matematiksel modeller

Table 1-Mathematical thin-layer drying models used for the approximation

\begin{tabular}{llll}
\hline Model no & Model ismi & Model eşitlĭgi & Referanslar \\
\hline 1 & Page & $M_{R}=\exp \left(-k t^{n}\right)$ & Page (1949) \\
2 & Modified Page & $M_{R}=a \exp \left[-\left(k t^{n}\right)\right]$ & Wang \& Singh (1978) \\
3 & Logarithmic & $M_{R}=a \exp (-k t)+c$ & Yagcioglu et al (1999) \\
4 & Wang ve Singh & $M_{R}=1+a t+b t^{2}$ & Wang \& Singh (1978) \\
5 & Midilli et al & $M_{R}=a \exp \left(-k t^{n}\right)+b t$ & Midilli et al (2002) \\
6 & Logistic & $M_{R}=a_{0} /(1+a \exp (k t))$ & Chandra \& Singh (1995) \\
7 & Jena ve Das & $M_{R}=a \exp (-k t+b \sqrt{t})+c$ & Jena \& Das (2007) \\
8 & Alibas Model & $M_{R}=a \exp \left(\left(-k t^{n}\right)+(b t)\right)+g$ & Yeni model \\
\hline$M_{R}$, ayrlabilir nem orani; $a, a_{0}, b, c, g$ katsayllar; $n, \operatorname{kurutma}$ sabiti; $k$ kurutma sabiti $\left(\min ^{-1}\right) ; t$, zaman (s)
\end{tabular}

artmasıla kurutma zamanında azalma meydana gelmiştir (Prabhanjan et al 1995; Drouzas \& Schubert 1996; Funebo \& Ohlsson 1998; Soysal 2004). Mikrodalga güç yoğunluğunun $17 \mathrm{~W} \mathrm{~g}^{-1}$ seviyesinden $15 \mathrm{~W} \mathrm{~g} \mathrm{~g}^{-1}$ seviyesine düşürülmesiyle kurutma zamanında yaklaşık 1.14 kat bir artış, 13 $\mathrm{W} \mathrm{g}^{-1}$ seviyesine düşürülmesiyle ise kurutma zamanında yaklaşık 1.29 kat bir artış kaydedilmiştir.

Farklı mikrodalga güç seviyesindeki kuruma hızları, nem oranına bağlı olarak Şekil 2'de verilmiştir. Asma yapraklarının 17,15 ve $13 \mathrm{~W} \mathrm{~g}^{-1}$ güç yoğunluklarıyla kurutulmasındaki ortalama kuruma hizları sirasiyla $0.338,0.323$ ve 0.291 [(kg su) (kg kuru madde $\left.\mathrm{s})^{-1}\right]$ olarak bulunmuştur. Mikrodalga güç yoğunluğu arttıkça ortalama kuruma hızında da bir artış meydana gelmektedir. Mikrodalga güç yoğunluğunun $13 \mathrm{~W} \mathrm{~g}^{-1}$ olduğu güç seviyesinde ondalık birim olarak kuru baza göre nem içeriği 2.2 oluncaya dek sabit hızla kuruma evresi gözlemlenmiş; ancak, bu noktadan sonra kuruma rejimi azalan hiz dönemine girmiştir. Mikrodalga güç yoğunluğunun $13 \mathrm{~W} \mathrm{~g}^{-1}$ güç yoğunluğuna göre nispeten daha yüksek olduğu 15 ve $17 \mathrm{~W} \mathrm{~g}^{-1}$ güç yoğunluklarında daha kısa sürelerde kuruma sağlandığ 1 için kuruma

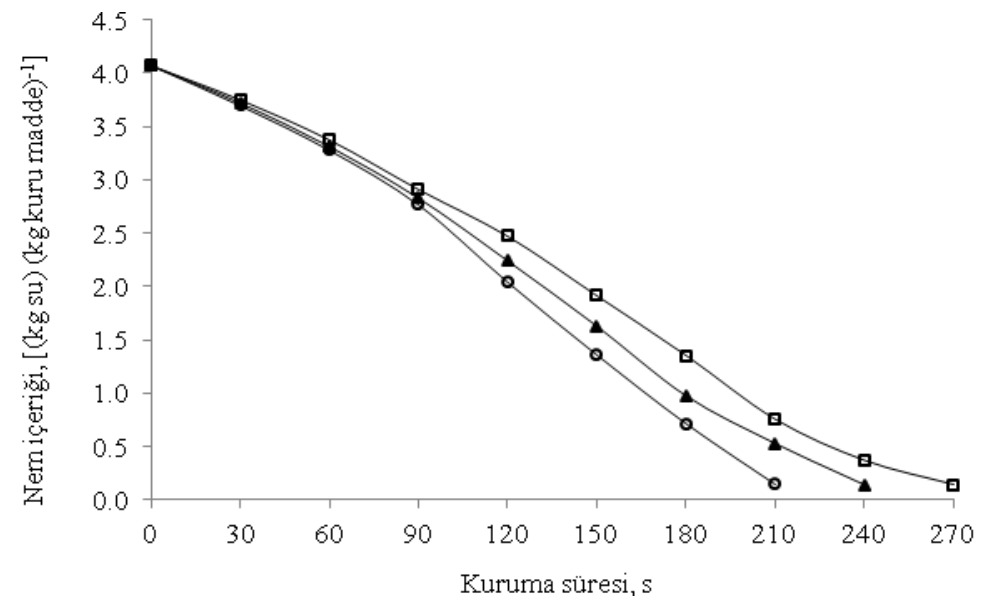

Şekil 1-Asma yapraklarının kuru baza göre kurutma eğrileri; $\square, 13 \mathrm{~W} \mathrm{~g}^{-1} ; \Delta, 15 \mathrm{~W} \mathrm{~g} \mathrm{~g}^{-1} ; \circ, 17 \mathrm{~W} \mathrm{~g}^{-1}$ Figure 1-The drying curve of grapevine leaves on dry basis; $\square, 13 \mathrm{~W} \mathrm{~g}^{-1} ; \mathbf{\Lambda}, 15 \mathrm{~W} \mathrm{~g}^{-1} ; \circ, 17 \mathrm{~W} \mathrm{~g}^{-1}$ 


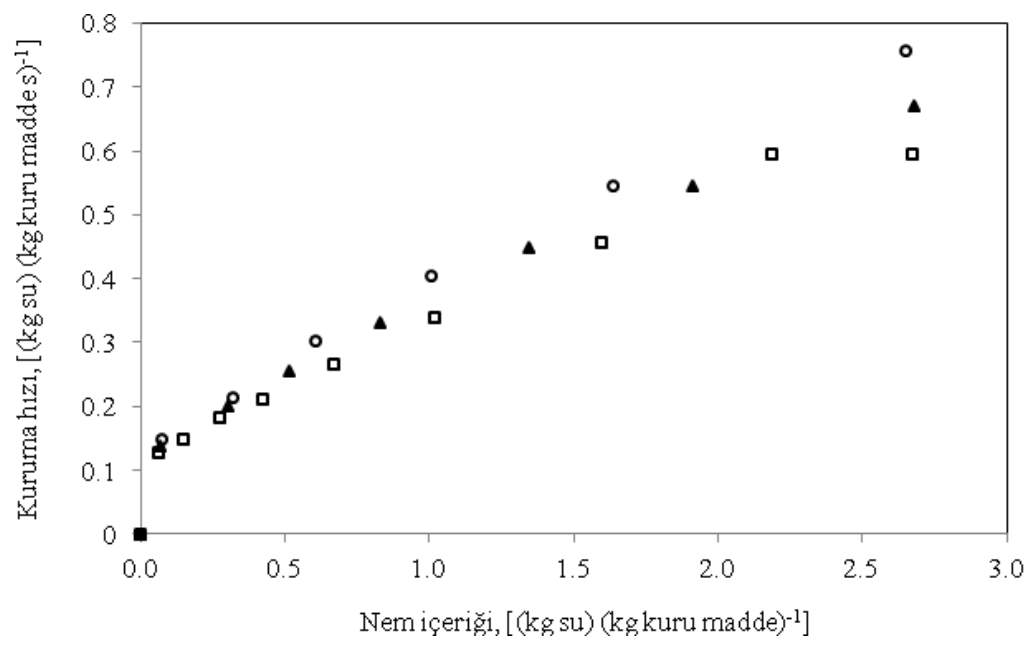

Şekil 2-Farklı mikrodalga güç yoğunluklarında asma yapraklarının kuruma hızı; $\square, 13 \mathrm{~W} \mathrm{~g}^{-1} ; \Delta, 15 \mathrm{~W} \mathrm{~g}^{-1} ; \circ, 17 \mathrm{~W} \mathrm{~g}^{-1}$

Figure 2-Drying rates of the grapevine leaves at different microwave power densities;

口, $13 \mathrm{Wg}^{-1} ; \mathbf{\Lambda}, 15 \mathrm{Wg}^{-1} ; \circ, 17 \mathrm{Wg}^{-1}$

işlemi azalan hız evresine girmeden sabit hızlı kuruma evresinde gerçekleşmiştir. $\mathrm{Bu}$ bulgular literatürdeki çeşitli araştırmacıların bulgularıyla paralellik göstermektedir (Funebo \& Ohlsson 1998; Sharma \& Prasad 2001; Maskan 2000; Soysal 2004; Alibas Ozkan et al 2007).

Çizelge 1'de tanımlanmış 8 farklı kurutma modeline ilişkin $R^{2}, S H, O K H$ ve $\chi^{2}$ istatistik verileriyle birlikte modellere ilişkin sabit ve katsayılar $\left(a, a_{0}, b, c, g, n\right.$ ve $\left.k\right)$ Çizelge 2'de verilmiştir. Çalışmada, $R^{2}$ değerinin " 1 " değerine en yakın olduğu ve $O K H, \chi^{2}$ ve $S H$ değerlerinin ise en küçük olduğu ince tabaka kurutma modeli, Alibas modelidir. Söz konusu mikrodalga güç yoğunlukları için tahmin verilerinin deneysel verilere en yakın olduğu model olan Alibas modeli, optimum model olarak tanımlanmıştır. Alibas modelinin $R^{2}$ değerleri sırasıyla $17 \mathrm{~W} \mathrm{~g}^{-1}$ mikrodalga güç yoğunluğunda $0.9998,15 \mathrm{~W} \mathrm{~g}^{-1}$ mikrodalga güç yoğunluğunda 0.9999 ve $13 \mathrm{~W} \mathrm{~g}^{-1}$ mikrodalga güç yoğunluğunda ise 0.9997 olarak hesaplanmıştır. Mikrodalga güç yoğunluğunun 13 $\mathrm{W} \mathrm{g}^{-1}$ olduğu kurutma seviyesinde ise regresyon katsayısının 0.9997 olduğu en iyi model olan Alibas modeline en yakın kurutma modeli 0.9980 regresyon katsayısı ile Midilli et al modelidir. Bu mikrodalga güç yoğunluğunda regresyon katsayısının en küçük olduğu model ise 0.9915 regresyon değeri ile Page modelidir. Alibas modeline ilişkin ki kare değerleri ise 17,15 ve 13 W $\mathrm{g}^{-1}$ mikrodalga güçleri için sırasıyla, $5.9516 \times 10^{-22}, 1.5763 \times 10^{-26}$ ve $4.7339 \times 10^{-23}$ olarak belirlenmiştir. Midilli et al modeline ait ki kare değerleri ise 17,15 ve $13 \mathrm{~W} \mathrm{~g}^{-1}$ güç yoğunlukları için sirasiyla, $1.6534 \times 10^{-08}, \quad 2.3456 \times 10^{-08}$ ve $3.1031 \times 10^{-08}$ olarak hesaplanmıştır.

Mikrodalga güç yoğunluğunun azalması ile $k$, $b$ ve $a$ katsayılarında sayıca bir azalma; $g$ ve $n$ katsayılarında ise sayıca bir artış meydana gelmiştir. Şekil 3'de, ayrılabilir nem oranının zamana bağlı olarak değişimi ile deneysel verilerle, en iyi model olan Alibas modeline ait tahmin verileri karşılaştırmalı olarak gösterilmiştir. Ozbek \& Dadali (2007) farklı ağırlıklardaki nane yapraklarını çeşitli mikrodalga güç aralığında kurutmuşlardır. Kurutulan nane yapraklarının çeşitli ince tabaka kurutma modelleri ile modellemişler ve deneysel verilere en yakın sonuçların Midilli et al modeli ile elde edildiğini saptamışlardır. Demirhan \& Ozbek (2011) kereviz yapraklarını 180 ile 900 W mikrodalga güç aralığında kurutmuşlar ve 


\section{Çizelge 2-Farklı mikrodalga kurutma yoğunlukları için çeşitli ince tabaka kurutma modellerinin katsayl, sabit ve istatistiki verileri}

Table 2-Coefficients and statistical results obtained from different thin-layer drying models for the different microwave power densities

\begin{tabular}{|c|c|c|c|c|c|c|c|c|c|}
\hline \multicolumn{4}{|c|}{$17 \mathrm{Wg}^{-1}$} & \multicolumn{3}{|c|}{$15 \mathrm{Wg}^{-1}$} & \multicolumn{3}{|c|}{$13 \mathrm{Wg}^{-1}$} \\
\hline No & $\mathrm{SH}$ & $O K H$ & $\chi^{2}$ & $\mathrm{SH}$ & $\mathrm{OKH}$ & $\chi^{2}$ & $\mathrm{SH}$ & $\mathrm{OKH}$ & $\chi^{2}$ \\
\hline 1 & $\begin{array}{ll}0.0377 & 0.9902\end{array}$ & $3.0360 \times 10^{-02}$ & $1.229 \times 10^{-03}$ & $\begin{array}{ll}0.0321 & 0.9927\end{array}$ & $2.823 \times 10^{-02}$ & $1.025 \times 10^{-03}$ & $0.0342 \quad 0.9915$ & $3.162 \times 10^{-02}$ & $1.249 \times 10^{-03}$ \\
\hline 2 & $0.0351 \quad 0.9929$ & $8.012 \times 10^{-03}$ & $1.027 \times 10^{-04}$ & $0.0292 \quad 0.9948$ & $7.784 \times 10^{-03}$ & $9.090 \times 10^{-05}$ & $0.0309 \quad 0.9939$ & $8.803 \times 10^{-03}$ & $1.107 \times 10^{-04}$ \\
\hline 3 & $0.0406 \quad 0.9905$ & $7.546 \times 10^{-08}$ & $9.110 \times 10^{-15}$ & $0.0316 \quad 0.9939$ & $1.447 \times 10^{-08}$ & $3.143 \times 10^{-16}$ & $0.0326 \quad 0.9932$ & $1.113 \times 10^{-04}$ & $1.771 \times 10^{-08}$ \\
\hline 4 & $0.0217 \quad 0.9967$ & $6.969 \times 10^{-03}$ & $6.476 \times 10^{-05}$ & $0.0285 \quad 0.9942$ & $1.177 \times 10^{-02}$ & $1.783 \times 10^{-04}$ & $0.0320 \quad 0.9926$ & $1.343 \times 10^{-02}$ & $2.257 \times 10^{-04}$ \\
\hline 5 & $0.0116 \quad 0.9994$ & $9.092 \times 10^{-05}$ & $1.653 \times 10^{-08}$ & $0.0136 \quad 0.9991$ & $1.141 \times 10^{-04}$ & $2.345 \times 10^{-08}$ & $0.0191 \quad 0.9980$ & $1.364 \times 10^{-04}$ & $3.103 \times 10^{-08}$ \\
\hline 6 & $0.0311 \quad 0.9944$ & $9.912 \times 10^{-03}$ & $1.572 \times 10^{-04}$ & $0.0247 \quad 0.9963$ & $9.418 \times 10^{-03}$ & $1.330 \times 10^{-04}$ & $0.0268 \quad 0.9954$ & $1.100 \times 10^{-02}$ & $1.729 \times 10^{-04}$ \\
\hline 7 & $0.0206 \quad 0.9980$ & $5.501 \times 10^{-05}$ & $6.052 \times 10^{-09}$ & $0.0229 \quad 0.9973$ & $1.866 \times 10^{-10}$ & $6.270 \times 10^{-20}$ & $0.0272 \quad 0.9960$ & $3.933 \times 10^{-11}$ & $2.579 \times 10^{-21}$ \\
\hline 8 & $\begin{array}{ll}0.0075 & 0.9998\end{array}$ & $1.493 \times 10^{-11}$ & $5.951 \times 10^{-22}$ & $\begin{array}{ll}0.0055 & 0.9999\end{array}$ & $8.370 \times 10^{-14}$ & $1.576 \times 10^{-26}$ & $\begin{array}{lll}0.0078 & 0.9997\end{array}$ & $4.865 \times 10^{-12}$ & $4.733 \times 10^{-23}$ \\
\hline \multicolumn{4}{|c|}{ No Kurutma katsayıları ve sabitleri } & \multicolumn{3}{|c|}{ Kurutma katsayılarl ve sabitleri } & \multicolumn{3}{|c|}{ Kurutma katsayılarl ve sabitleri } \\
\hline 1 & \multicolumn{3}{|c|}{$\mathrm{k}=0.1744 \quad \mathrm{n}=2.0825$} & \multicolumn{3}{|c|}{$\mathrm{k}=0.1635 \quad \mathrm{n}=1.9751$} & \multicolumn{3}{|c|}{$\mathrm{k}=0.1397 \quad \mathrm{n}=1.9534$} \\
\hline 2 & \multicolumn{3}{|c|}{$\mathrm{k}=0.1387 \quad \mathrm{n}=2.2878 \quad \mathrm{a}=0.9604$} & \multicolumn{3}{|c|}{$\mathrm{k}=0.1325 \quad \mathrm{n}=2.1471 \quad \mathrm{a}=0.9631$} & \multicolumn{3}{|c|}{$\mathrm{k}=0.1086 \quad \mathrm{n}=2.1436 \quad \mathrm{a}=0.9590$} \\
\hline 3 & \multicolumn{3}{|c|}{$\begin{array}{l}\mathrm{k}=5.687810^{-05} \mathrm{a}=5.0213 \times 10^{03} \\
\mathrm{c}=-5.0202 \times 10^{03}\end{array}$} & \multicolumn{3}{|c|}{$\begin{array}{l}\mathrm{k}=8.555610^{-05} \mathrm{a}=2.9850 \times 10^{03} \\
\mathrm{c}=-2.9840 \times 10^{03}\end{array}$} & \multicolumn{3}{|c|}{$\begin{array}{l}\mathrm{k}=0.0001 \mathrm{a}=2.250710^{03} \\
\mathrm{c}=-2.2496 \times 10^{03}\end{array}$} \\
\hline 4 & \multicolumn{3}{|c|}{$\mathrm{a}=-0.1894 \mathrm{~b}=-0.0265$} & \multicolumn{3}{|c|}{$a=-0.2029 \quad b=-0.0119$} & \multicolumn{3}{|c|}{$\mathrm{a}=-0.1932 \quad \mathrm{~b}=-0.0072$} \\
\hline 5 & \multicolumn{3}{|c|}{$\begin{array}{l}k=0.1047 \quad n=1.8725 \quad a=0.9919 \\
b=-0.0859\end{array}$} & \multicolumn{3}{|c|}{$\begin{array}{l}k=0.1273 \quad n=1.7714 \quad a=0.9887 \\
b=-0.0496\end{array}$} & \multicolumn{3}{|c|}{$\begin{array}{l}k=0.1134 \quad n=1.7677 \quad a=0.9853 \\
b=-0.0400\end{array}$} \\
\hline 6 & \multicolumn{3}{|c|}{$\mathrm{k}=1.5131 \quad \mathrm{a}_{0}=1.0261 \quad \mathrm{a}=0.0527$} & \multicolumn{3}{|c|}{$\mathrm{k}=1.3112 \quad \mathrm{a}_{0}=1.0432 \mathrm{a}=0.0673$} & \multicolumn{3}{|c|}{$\mathrm{k}=1.1896 \quad \mathrm{a}_{0}=1.0404 \mathrm{a}=0.0682$} \\
\hline 7 & \multicolumn{3}{|c|}{$\begin{array}{l}k=0.0003 \quad a=1.457410^{3} \quad b=0.0001 \\
c=-1.4564 \times 10^{3}\end{array}$} & \multicolumn{3}{|c|}{$\begin{array}{l}k=0.0836 \quad a=4.3532 \quad b=0.0394 \\
c=-3.3573\end{array}$} & \multicolumn{3}{|c|}{$\begin{array}{l}\mathrm{k}=0.0980 \quad \mathrm{a}=3.4547 \quad \mathrm{~b}=0.0482 \\
\mathrm{c}=-2.4599\end{array}$} \\
\hline 8 & \multicolumn{3}{|c|}{$\begin{array}{l}k=0.0362 \quad n=2.8457 \quad a=1.1519 \quad b=- \\
0.1470 \quad g=-0.1534\end{array}$} & \multicolumn{3}{|c|}{$\begin{array}{l}k=0.0283 \quad n=2.9893 \quad a=1.0556 \quad b=- \\
0.1648 \quad g=-0.0554\end{array}$} & \multicolumn{3}{|c|}{$\begin{array}{l}k=0.0101 \quad n=3.6607 \quad a=1.0086 \quad b=- \\
0.1878 \quad g=-0.0038\end{array}$} \\
\hline
\end{tabular}

$S H$, standart hata; $R^{2}$, regresyon katsayısi; $O K H$, ortalama karesel hata; $\chi^{2}$, ki kare

kurutma süresini mikrodalga gücüne bağlı olarak 25 g kurutma örnekleri için 8-34 dakika olarak tespit etmişlerdir. Çalışmada kurutma eğrileri çeşitli ince tabaka kurutma modellerine göre modellenmiş ve laboratuar verilerine en yakın sonuçları veren modelin Midilli et al modeli olduğunu saptamışlardır. Demirhan \& Ozbek (2010a) semizotunu mikrodalga enerjisiyle kurutmuşlar ve çeşitli modellerle modellemişlerdir. Deneysel verilere en yakın sonuçları veren modelin Midilli et al eşitliği olduğunu saptamışlardır. Demirhan \& Ozbek (2010c) fesleğeni 180 ile $900 \mathrm{~W}$ mikrodalga güç aralığında kurutmuşlar ve çeşitli modellerle modellemişlerdir. Buna göre deneysel verilere en yakın sonuçları veren ince tabaka kurutma modelinin Logarithmic model olduğu sonucuna varmışlardır. Soysal et al (2006) 900 W mikrodalga gücünde kuruttukları maydanozu 11 farklı kurutma modeli ile modellemişler ve en optimum modelin Midilli et al Modeli olduğunu belirlemişlerdir.

Tüm mikrodalga güç yoğunlukları içinde $R^{2}$ 'nin en yüksek çıkması ile optimum model olarak tayin edilen Alibas modeline ilişkin saniye biriminden zamana $(t)$ bağlı $M_{R}$ eşitliği Arrhenius tip matematiksel formülle mikrodalga güç yoğunluklarını da içerecek şekilde sabit ve katsayılarına ayrıştırılmıştır. Mikrodalga ışınlarla kurutulan çeşitli yapraklı tarımsal ürünlerin modellemelerini Arrhenius tip matematiksel formülle bileşenlerine ayıran çok sayıda literatür çalışması bulunmaktadır (Ozbek \& Dadali 2007; Demirhan \& Ozbek 2011; Demirhan \& Ozbek 2010a \& 2010c). Çizelge 3'de Alibas Modeli ile Arrhenius tip matematiksel eşitliğin varyasyonuna ilişkin sabit ve katsayılar $\left(k_{1}, k_{2}, n_{1}, n_{2}, a_{1}, a_{2}, b_{1}\right.$, $b_{2}, g_{1}$ ve $g_{2}$ ) yer almaktadır. Aşağıdaki eşitlikte 


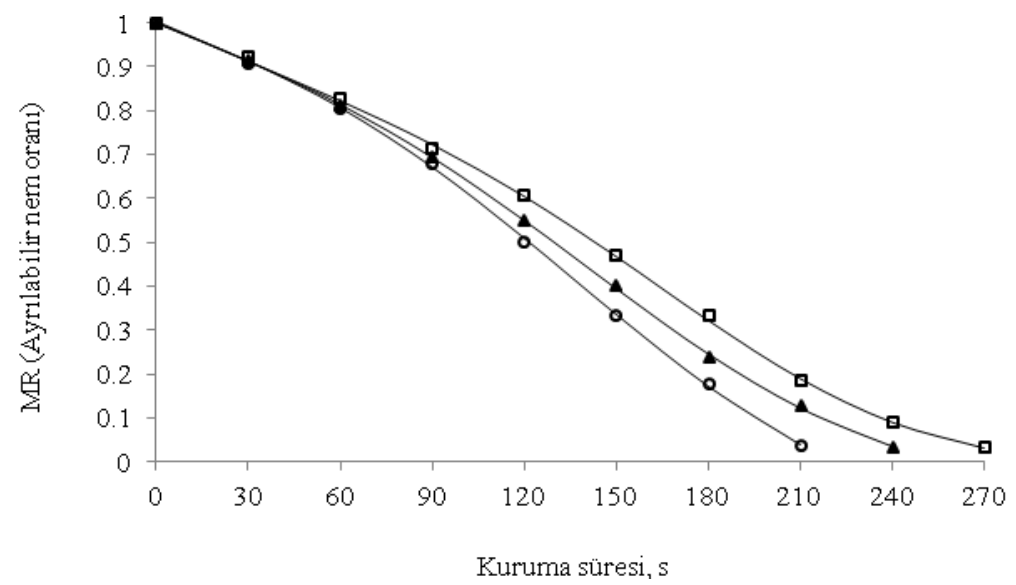

Şekil 3-Zamana bağlı ayrılabilir nem oranı, asma yapraklarının çeşitli mikrodalga güç yoğunlukları ile kurutulması sırasında elde edilen deneysel verilerle Alibas eşitliğine iliş̧kin tahmin verilerinin karşılaştırılması; $\square, 13 \mathrm{~W} \mathrm{~g}^{-1}$; $\Delta, 15 \mathrm{~W} \mathrm{~g}^{-1} ; \circ, 17 \mathrm{~W} \mathrm{~g}^{-1}$; — , model tahmini Figure 3-Moisture ratio versus time, comparing experimental curve with the predicted one through Alibas's equation for grapevine leaves under various microwave power densities; $\square, 13 \mathrm{~W} \mathrm{~g}^{-1} ; \mathbf{\Lambda}, 15 \mathrm{~W} \mathrm{~g}^{-1}$; ०, $17 \mathrm{Wg}$ ${ }^{1} ;-$, predicted

mikrodalga güç yoğunluğunu içeren zamana bağlı $M_{R}$ eşitliği görülmektedir:

$$
M_{R}=\left(a_{1} \exp \left(\frac{a_{2}}{P_{D}}\right)\right) \exp \left[\left(-\left(k_{1} \exp \left(\frac{k_{2}}{P_{D}}\right)\right) t\left(\frac{\left(n_{1} \exp \left(\frac{n_{2}}{P_{D}}\right)\right)}{P_{D}}\right)+\left(\left(b_{1} \exp \left(\frac{b_{2}}{P_{D}}\right)\right) t\right)\right]+\left(g_{1} \exp \left(\frac{g_{2}}{P_{D}}\right)\right)\right.
$$

\subsection{Askorbik asit (C vitamin) içeriği ve renk parametreleri}

Farklı mikrodalga güç yoğunluklarında kurutulan asma yapraklarının askorbik asit içeriği, $L, a, b, C$ ve $\alpha$ renk parametreleri ile taze ürünün askorbik asit içeriği ve renk parametreleri ile karşılaştırmalı olarak Çizelge 4'de verilmiştir. Taze ürünün askorbik asit içeriği ile kurutulan asma yapraklarının askorbik asit içeriği arasında $P<0.01$ önem seviyesinde bir farklılık bulunmuştur. Hem kurutma süresi hem de mikrodalga enerjisi bakımından birbirine yakın olan 17,15 ve $13 \mathrm{~W} \mathrm{~g}^{-}$ ${ }^{1}$ mikrodalga güç yoğunluklarıyla kurutulan asma yapraklarının askorbik asit içeriği arasında önemli bir fark bulunamamıştır. Mikrodalga kurutma süresinin uzaması ile kurutulan materyallerin askorbik asit içeriğinde önemli ölçüde azalma oluştuğu literatürdeki bazı araştırmacılar tarafından saptanmıştır (Zhang \& Hamauzu 2004; Nindo et al 2003).
Taze asma yaprakları ile 17,15 ve $13 \mathrm{~W} \mathrm{~g}^{-1}$ mikrodalga güç yoğunluklarında kurutulan asma yapraklarının yeşillik oranını veren $a$ değeri arasinda $P<0.01$ önem seviyesinde bir fark bulunmuştur. Taze yaprakların yeşillik değeri 9.45 olarak belirlenmiştir. Asma yapraklarının yeşilliği bakımından taze ürüne en yakın renk değerinin -8.99 değeri ile $15 \mathrm{~W} \mathrm{~g}^{-1}$ mikrodalga güç yoğunluğunda $(750 \mathrm{~W})$ olduğu saptanmıştır. Askorbik asit içeriği bakımından bu güç düzeyini sirasiyla $13 \mathrm{~W} \mathrm{~g}^{-1}(650 \mathrm{~W})$ ve $17 \mathrm{~W} \mathrm{~g}^{-1}(850 \mathrm{~W})$ mikrodalga güç yoğunlukları izlemiştir. Taze ürün ile 17,15 ve $13 \mathrm{~W} \mathrm{~g}^{-1}$ mikrodalga güç yoğunluklarında kurutulan asma yapraklarının sarılık oranını veren $b$ değeri arasında $P<0.10$ önem seviyesinde bir fark bulunmuştur. Asma yapraklarının sarılık değeri bakımından taze ürüne en yakın renk değerinin $15 \mathrm{~W} \mathrm{~g}^{-1}$ mikrodalga güç yoğunluğunda $(750 \mathrm{~W})$ olduğu belirlenmiştir. Askorbik asit içeriği bakımından bu güç düzeyini sirasiyla $13 \mathrm{~W} \mathrm{~g}^{-1}(650 \mathrm{~W})$ ve $17 \mathrm{~W} \mathrm{~g}^{-1}(850 \mathrm{~W})$ mikrodalga güç yoğunlukları takip etmiştir. Alibas-Ozkan et al 2007 sspanak yapraklarını 1000-90 W arasında 8 farklı mikrodalga gücüyle 
Çizelge 3-Alibas Model eşitliği ile Arrhenius tip matematiksel eşitliğin kombinasyonu ile elde edilen sabit ve katsaylar

Table 3-Constants and coefficients formed with the combination of Alibas Model and Arrhenius type formula

\begin{tabular}{lccc}
\hline Katsayı & \multicolumn{3}{c}{ Mikrodalga güç yoğunluğu $\left(P_{D}\right)$} \\
\cline { 2 - 4 } ve sabitler & $17 \mathrm{Wg}^{-1}$ & $15 \mathrm{Wg}^{-1}$ & $13 \mathrm{Wg}^{-1}$ \\
\hline$a_{1}$ & 0.8750 & 0.8913 & 0.5294 \\
$a_{2}$ & 4.6690 & 2.5415 & 8.3697 \\
$b_{1}$ & -0.2101 & -0.3482 & -0.2361 \\
$b_{2}$ & -6.0655 & -11.2133 & -2.9762 \\
$g_{1}$ & -0.2124 & -0.0881 & -0.0018 \\
$g_{2}$ & -5.5633 & -6.8549 & 6.6317 \\
$k_{1}$ & 0.0742 & 0.0773 & 0.0300 \\
$k_{2}$ & -12.2115 & -15.0461 & -14.2128 \\
$n_{1}$ & 2.8760 & 2.0507 & 5.2131 \\
$n_{2}$ & -0.1836 & 5.6598 & -4.6060 \\
\hline
\end{tabular}

Çizelge 4-Çeşitli mikrodalga güç yoğunlukları ile kurutulmuş asma yapraklarının bazı kalite parametrelerinin karşılaştırılması

Table 4-Comparison between microwave power densities for some quality parameters during grapevine drying

\begin{tabular}{|c|c|c|c|c|c|c|}
\hline \multirow{2}{*}{$\begin{array}{l}\text { Kurutma } \\
\text { yöntemleri }\end{array}$} & \multirow{2}{*}{$\begin{array}{l}\text { Askorbik asit }^{* *} \\
\left(\mathrm{mg} 100^{-1} \mathrm{~g}^{-1}\right)\end{array}$} & \multicolumn{5}{|c|}{ Renk Parametreleri } \\
\hline & & $L^{*}$ & $a^{*}$ & $b^{* *}$ & $C^{*}$ & $\alpha^{\ddot{d d d}}$ \\
\hline Taze & $118.13^{\mathrm{a}} \pm 2.23$ & $37.44^{\mathrm{a}} \pm 0.91$ & $-9.45^{\mathrm{a}} \pm 0.34$ & $14.67^{\mathrm{a}} \pm 0.55$ & $17.45^{\mathrm{a}} \pm 0.46$ & $122.83 \pm 2.07$ \\
\hline $17 \mathrm{~W}$ & $99.09^{\mathrm{b}} \pm 2.22$ & $33.16^{\mathrm{b}} \pm 1.02$ & $-8.28^{\mathrm{c}} \pm 0.17$ & $13.92^{\mathrm{bc}}$ & $16.20^{\mathrm{ab}} \pm 0.16$ & $120.76 \pm 0.15$ \\
\hline $15 \mathrm{Wg}^{-1}$ & $103.86^{\mathrm{b}} \pm 2.87$ & $34.68^{\mathrm{b}} \pm 0.42$ & $-8.99^{\mathrm{ab}} \pm 0.08$ & $14.46^{\mathrm{ab}} \pm 0.44$ & $17.03^{\mathrm{bc}} \pm 0.36$ & $121.86 \pm 0.79$ \\
\hline $13 \mathrm{Wg}^{-1}$ & $101.95^{\mathrm{b}} \pm 2.28$ & $34.16^{\mathrm{b}} \pm 0.71$ & $-8.85^{b} \pm 0.15$ & $13.99^{c} \pm 0.15$ & $16.56^{\mathrm{c}} \pm 0.21$ & $122.39 \pm 0.22$ \\
\hline
\end{tabular}

$L$, rengin parlaklığı; $a$, rengin yeşilliği; $b$, rengin sarılık değeri; $C$, rengin kroması; $\alpha^{\circ}$, renk açısı

** sütunlar arasında $P<0.01$ önem seviyesinde farklılık bulunmuştur.

*** sütunlar arasında $P<0.10$ önem seviyesinde farklılık bulunmuştur

öd sütunlar arasında farklılık önemli değildir

kurutmuş, taze ürüne en yakın renk değerinin 750 W mikrodalga gücünde meydana geldiğini belirlemiştir.

\section{Sonuçlar}

İlk nem içeriği kuru baza göre 4.08 olan asma yapraklar1 0.144 yb'ye oluncaya dek 17,15 ve 13 $\mathrm{W} \quad \mathrm{g}^{-1}$ mikrodalga güç yoğunluklarında kurutulmuştur. Kurutma işlemleri 210-270 saniyede tamamlanmıştır. Çalışmada deneysel veriler farklı modeller kullanılarak modellenmiş ve Alibas modelinin tahmin verileri deneysel verilere en yakın sonuçları vermiştir. Üç farklı mikrodalga güç yoğunluğunda kurutulmuş asma yapraklarının renk ve askorbik asit içerikleri ölçülmüş ve taze ürünün renk ve askorbik asit içeriğine en yakın değerlerin $15 \mathrm{~W} \mathrm{~g}^{-1}$ mikrodalga güç yoğunluğunda $(750 \quad \mathrm{~W})$ elde edildiği saptanmıştır.

\begin{tabular}{|ll|}
\hline Simgeler Dizini & \\
\hline$\alpha$ & renk açısı \\
$\chi^{2}$ & ki kare \\
$a$ & rengin kırmızılık / yeşillik oranı \\
$b$ & rengin sarılık / mavilik oranı \\
\hline
\end{tabular}




\begin{tabular}{|c|c|}
\hline$b_{1}, b_{2}, g_{1}, g_{2}$ & Alibaş eşitliğine ilişkin sabit ve katsayılar \\
\hline$C$ & rengin kroması \\
\hline$D R$ & kuruma hızı, $\left[(\mathrm{kg} \mathrm{su})(\mathrm{kg} \text { kuru madde s})^{-1}\right]$ \\
\hline$k, a, a_{0}, b, c, g$, ve $n$ & kuruma sabiti ve katsayıları \\
\hline$k_{1}, k_{2}, n_{1}, n_{2}, a_{1}, a_{2}$ & Alibaş eşitliğine ilişkin sabit ve katsayılar \\
\hline$L$ & rengin parlaklığ1 \\
\hline$M$ & herhangi bir andaki nem içeriği, $\left[(\mathrm{kg} \mathrm{su})\left(\mathrm{kg}\right.\right.$ kuru madde $\left.\left.{ }^{-1}\right)\right]$ \\
\hline$M_{e}$ & denge nem içeriği, [(kg su) (kg kuru madde $\left.\left.{ }^{-1}\right)\right]$ \\
\hline$M_{\mathrm{o}}$ & ilk nem içeriği, $\left[(\mathrm{kg} \mathrm{su})\left(\mathrm{kg}\right.\right.$ kuru madde $\left.\left.{ }^{-1}\right)\right]$ \\
\hline$M R$ & ayrılabilir nem oranı \\
\hline$M_{t}$ & her hangi bir $t$ anındaki nem içeriği, $\left[(\mathrm{kg} \mathrm{su})\left(\mathrm{kg}\right.\right.$ kuru madde $\left.\left.{ }^{-1}\right)\right]$ \\
\hline$M_{t+\mathrm{d} t}$ & $t+\mathrm{d} t$ aralığındaki nem içeriği, [(kg su) $\left(\mathrm{kg}\right.$ kuru madde $\left.\left.{ }^{-1}\right)\right]$ \\
\hline$n_{i}$ & sabit ve katsayıların sayısı \\
\hline$N$ & toplam gözlem sayısı \\
\hline $\mathrm{OKH}$ & ortalama karesel hata \\
\hline$P_{D}$ & mikrodalga güç yoğunluğu, $\mathrm{W} \mathrm{g}^{-1}$ \\
\hline$R^{2}$ & regresyon katsayısı \\
\hline SH & standart hata \\
\hline$W_{0}$ & örneklerin ilk baştaki ağırlı̆̆ı, $\mathrm{kg}$ \\
\hline$W_{k}$ & örneklerin toplam kuru ağırlığı, kg \\
\hline$t$ & zaman, s \\
\hline
\end{tabular}

\section{Kaynaklar}

Alibas I (2006). Characteristics of chard leaves during microwave, convective, and combined microwaveconvective drying. Drying Technology 24(1):14251435

Alibas I (2007). Energy consumption and colour characteristics of nettle leaves during microwave, vacuum and convective drying. Biosystems Engineering 96(4):495-502

Alibas I (2010). Correlation of drying parameters, ascorbic acid and color characteristics of nettle leaves during microwave-, air- and combined microwave-air-drying. Journal of Food Process Engineering 33(2): 213-233

Alibas Ozkan I, Akbudak B \& Akbudak N (2007). Microwave drying characteristics of spinach. Journal of Food Engineering 78:577-583

Chandra P K \& Singh R P (1995). Applied numerical methods for food and agricultural engineers. CRC Press, Boca Raton, FL, pp. 163-167
Cihan A, Kahveci K \& Hacıhafızoğlu O (2007). Modelling of intermittent drying of thin layer rough rice. Journal of Food Engineering 79:293-298

Demirhan E \& Ozbek B (2011). Colour change kinetics of celery leaves undergoing microwave drying. Chemical Engineering Communications 198(10):1189-1205

Demirhan E \& Özbek B (2010a). Drying kinetics and effective moisture diffusivity of purslane undergoing microwave heat treatment. Korean Journal of Chemical Engineering 27(5):1377-1383

Demirhan E \& Özbek B (2010b). Rehydration kinetics of microwave dried basil. Journal of Food Processing and Preservation 34(4):664-680

Demirhan E \& Özbek B (2010c). Microwave drying characteristics of basil. Journal of Food Processing and Preservation 34(3):476-494

Doymaz İ, Tugrul N \& Pala M (2006). Drying characteristics of dill and parsley leaves. Journal of Food Engineering 77:559-565 
Drouzas A E \& Schubert H (1996). Microwave application in vacuum drying of fruits. Journal of Food Engineering 28: 203-209

Eriş A \& Şeniz V (1997). Bahçe Bitkileri. Uludağ Üniversitesi Ziraat Fakültesi Ders Notları No:28, Ders Kitab1: 192, Bursa

Ertekin C \& Yaldiz O (2004). Drying of eggplant and selection of a suitable thin layer Drying model. Journal of Food Engineering 63:349-359

Funebo T \& Ohlsson T (1998). Microwave-assisted air dehydration of apple and mushroom. Journal of Food Engineering 38(3): 353-367

Guarte R C (1996). Modeling the drying behavior of copra and development of a natural convection dryer for production of high quality copra in the Philippines. $\mathrm{PhD}$ Thesis (Unpublished), Dissertation, Hohenheim, Stuttgart, Germany

Jena S \& Das H (2007). Modeling for vacuum drying characteristics of coconut presscake. Journal of Food Engineering 79:92-99

Kadlec P, Rubecova A, Hinkova A, Kaasova J, Bubnik Z \& Pour V (2001). Processing of yellow pea by germination, microwave treatment and drying. Innovative Food Science and Emerging Technologies 2: 133-137

Karaaslan S N \& Tunçer İ K (2008). Development of a drying model for combined microwave-fan assisted convection drying of spinach. Biosystems Engineering 100:44-52

Maskan M (2000). Microwave/air and microwave finish drying of banana. Journal of Food Engineering 44: 71-78

Maskan M (2001). Drying, shrinkage and rehydration characteristics of kiwifruits during hot air and microwave drying. Journal of Food Engineering 48(2): 177-182

Midilli A \& Kucuk H (2003). Mathematical modeling of thin layer drying of pistachio by using solar energy. Energy Conversion and Management 44(7):1111-1122

Midilli A, Kucuk H \& Yapar Z (2002). A new model for single layer drying. Drying Technology 20(7):1503-1513

Nindo C I, Sun T, Wang S W, Tang J \& Powers J R (2003). Evaluation of drying technologies for retention of physical quality and antioxidants in asparagus (Asparagus officinalis, L.). Lebensm.Wiss.u.-Technology 36: 507-516

Özbek B \& Dadali G (2007). Thin-layer drying characteristics and modelling of mint leaves undergoing microwave treatment. Journal of Food Engineering 83: 541-549

Özdemir M \& Devres Y O (1999). The thin layer drying characteristics of hazelnuts during roasting. Journal of Food Engineering 42: 225-233

Page G (1949). Factors influencing the maximum rates of air-drying shelled corn in thin layer. MS Thesis, Department of Mechanical Engineering, Purdue University (Unpublished), West Lafayette, IN, USA

Prabhanjan D G, Ramaswamy H S \& Raghavan G S V (1995). Microwave assisted convective air drying of thin layer carrots. Journal of Food Engineering 25: 283-293

Sharma G P \& Prasad S (2001). Drying of garlic (Allium sativum) cloves by microwave-hot air combination. Journal of Food Engineering 50: 99105

Soysal Y (2004). Microwave drying characteristics of parsley. Biosystems Engineering 89(2): 167-173

Soysal Y, Oztekin S \& Eren O (2006). Microwave drying of parsley: modelling, kinetics, and energy aspects. Biosystems Engineering 93(4): 403-413

Toğrul H (2006). Suitable drying model for infrared drying of carrot. Journal of Food Engineering 77: 610-619

Torringa E, Esveld E, Scheewe I, van den Berg R \& Bartels P (2001). Osmotic dehydration as a pretreatment before combined microwave-hot-air drying of mushrooms. Journal of Food Engineering 49: $185-191$

Wang C Y \& Singh R P (1978). A single layer drying equation for rough rice. ASAE Paper No: 78-3001, ASAE, St. Joseph, MI

Yağcığlu A (1999). Tarım Ürünleri Kurutma Tekniği. EÜ Ziraat Fakültesi, İzmir

Yagcioglu A, Degirmencioglu A \& Cagatay F (1999). Drying characteristics of laurel leaves under different drying conditions. In: Proceedings of the 7 th International Congress on Agricultural Mechanization and Energy, 565-569, 26-27 May, Adana, Turkey

Zhang D \& Hamauzu Y (2004). Phenolics, ascorbic acid, carotenoids and antioxidant activity of broccoli and their changes during conventional and microwave cooking. Food Chemistry 88: 503-509 